Candy reports that he has calculated parabolic elements and an ephemeris for comet 1972f, as shown below. The elements are based on 3 accurate observations covering an arc of 5 days, and the residuals are all less than $1^{\prime \prime}$.

\begin{tabular}{|c|c|c|c|c|}
\hline \multirow{2}{*}{\multicolumn{5}{|c|}{$\begin{array}{l}T=1972 \text { Mar. } 27.726 \text { E.T. } \\
q=0.9275 \text { A.U. }\end{array}$}} \\
\hline & & & & \\
\hline 1972 E.T. & $\alpha_{1950}$ & $\delta_{1950}$ & $\Delta$ & $r$ \\
\hline Apr. 3.0 & $0^{\mathrm{h}} 15 \mathrm{~m} 8$ & $-44^{\circ} 33^{\prime}$ & 1.171 & 0.934 \\
\hline 8.0 & 0558 & -4741 & & \\
\hline 18.0 & 150.3 & -5007 & 0.961 & 0.972 \\
\hline 18.0 & 300.0 & -5042 & & \\
\hline
\end{tabular}

4. KOHOUTEK OBJECT AKSNES $19504 \quad 11125004121141190325811850036211543$ 003161170900272118320023111950001921210390344811140015712213112076950784703 APOLLO TYPE ASTEROID MAGNITUDE SEVENTEEN SEKANINA

Sekanina communicates the following ephemeris by Aksnes for the object discovered by Kohoutek. The object is an Apollo-type asteroid.

\begin{tabular}{|c|c|c|c|c|c|c|}
\hline 1971 & E.T. & $\alpha_{1950}$ & $\delta_{1950}$ & 4 & $r$ & Mag \\
\hline Nov. & 25.0 & $0^{\mathrm{h}} 41^{\mathrm{m}} \cdot 2$ & $-14^{\circ} 11^{\prime}$ & 0.325 & 1.185 & 17 \\
\hline & 27.0 & 036.2 & -1543 & & & \\
\hline & 19.0 & 0316 & -1709 & & & \\
\hline Dec. & 1.0 & 0272 & -1832 & & & \\
\hline & 3.0 & 023.1 & -1950 & & & \\
\hline & 5.0 & $\begin{array}{lll}0 & 192\end{array}$ & -2103 & 0.344 & 1.114 & \\
\hline & 7.0 & $\begin{array}{lll}0 & 15 & 7\end{array}$ & -2213 & & & \\
\hline
\end{tabular}

5. HONDA SERPENS NOVA HONDA 1900100215 8//// 1825720238030534076441548 BRIGHTNESS INCREASING HIROSE

Hirose repo:ts that Honda has discovered and observed a nova in Serpens, as shown below. The brightness is increasing.

$\begin{array}{rrrr}\text { 1970 U.T. } & \alpha_{1900} & \delta_{1900} & m_{v} \\ \text { Feb. } 15.8 & 18^{\mathrm{h}} 25^{\mathrm{m}} \mathrm{m} & +2^{\circ} 38^{\prime} & 5.3\end{array}$

6. N3811 SUPERNOVA ROSINO $195010920911386247580412 / 20005200038998240264$ ASIAGO

The Asiago Astrophysical Observatory communicates the observation by Rosino of a supernova in NGC $3811\left(\alpha=11^{\mathrm{h}} 38^{\mathrm{m}} \cdot 6, \delta=+47^{\circ} 58^{\prime}\right.$, equinox 1950.0), $5^{\prime \prime}$ east and $3^{\prime \prime}$ north of the nucleus. On 1969 Feb. 9 U.T. the photographic magnitude was 12.

\title{
$\checkmark$ PUBLICATIONS OF THE INTERNATIONAL ASTRONOMICAL UNION
}

Reference is made to the Report of the Executive Committee, pp. 27-29 and to Information Bulletin Nos. 28, 29 and 30.

\section{SYMPOSIA OF THE INTERNATIONAL ASTRONOMICAL UNION}

Reference is made to the Report of the Executive Committee, pp. 6-7 and to Information Bulletin Nos. 28, 29 and 30. 